\title{
Material Balance Studies on Cigarettes Containing 3-Phenyl-5-methyl-1,2,4-oxadiazole*
}

\author{
by Robert S. Marmor and Harry 7. Minnemeyer \\ Lorillard, A Division of Loews Theatres, Inc., Research Center, Greensboro, N. C., U.S.A.
}

\section{INTRODUCTION}

Recent interest in 3-phenyl-5-methyl-1,2,4-oxadiazole (PMO) as a potential cigarette additive has been prompted by a number of animal inhalation experiments using cigarettes containing this compound $(x-9)$. These experiments have indicated that PMO is a mediator in the biological alterations induced in the respiratory tract by chemical irritants. In this paper, the distribution of PMO or its combustion products into smoke or residues has been followed with both unlabeled and radiocarbon labeled material.

\section{RESULTS}

\section{Results with Unlabeled PMO}

For the experiments with the unlabeled compound, cigarettes containing $1.5 \%$ PMO were manufactured and packaged on conventional machinery with a commercial blend of tobacco under standard conditions. The concentration of PMO in the packaged cigarettes was shown to remain relatively uniform and constant over many months. The selection of cigarettes for analysis on the basis of weight and draw was not practical because of the ready loss of PMO by volatilization from individual cigarettes exposed to ambient air.

The smoking experiments with unlabeled cigarettes were performed with essentially the same apparatus, and under the same conditions as described in detail for the labeled cigarettes. The uniformity of the machine-made cigarettes gave reproducible results for the distribution of PMO in smoke and butt. Although the results were reproducible, only $75-80 \%$ of the PMO originally present on the cigarette could be recovered. Chromatographic analyses of the butt, tar, and gas phase did not reveal anything unusual. Presumably the missing PMO had undergone decomposition.

The results of a number of experiments with unlabeled PMO are summarized by the data presented in Table 1 .

* Received for publication: 17th March, 1975.

\section{Results with Labeled PMO}

Cigarettes prepared with radiocarbon labeled PMO $[5-14 \mathrm{C}]$ provided a means of detecting PMO and its combustion products. Several recent papers in the tobacco literature make use of labeled compounds as tracers for material balance studies (10-14), including papers by Jenkins et al. describing a smoking machine system for the quantitative recovery of the label as carbon dioxide $(15,16)$.

It was not feasible to reproduce Jenkins' relatively complex apparatus for this study. A simpler approach using Cambridge filter pads followed by a series of gas bubbler wash bottles was used instead. No problems were encountered in preparing homogeneous liquid scintillation samples from hexane, toluene, or water aliquots and commercial $l s c^{* *}$ cocktails. Quenching was in most cases minor and phosphorescence was not observed. The normally employed organic amines (Hyamine-10X, phenethylamine) were not needed for carbon dioxide absorption; instead, an aqueous sodium hydroxide solution was employed. Carbon monoxide was also trapped in a gas bubbler washing bottle, containing a silver oxide-amine solution (17), which

Table 1. Material balance results for percentage recovery of unlabeled PMOa.

\begin{tabular}{l|c}
\hline Source & $\%$ PMOb \\
\hline Mainstream (particulate) & $28.46 \pm 2.55$ \\
Mainstream (gas phase) & 0.00 \\
Sidestream (particulate) & $16.12 \pm 2.39$ \\
Sidestream (gas phase) & $5.62 \pm 2.71$ \\
Buttc & $27.30 \pm 1.83$ \\
Total & $77.51 \pm 2.06$ \\
\end{tabular}

a: $85 \mathrm{~mm}$ cigarettes conteining $1.5 \%$ PMO, smoked to $23 \mathrm{~mm}$ butt length, standard smoking conditlons, six cigariettes smoked per run.

b: \pm relative standard error (5 runs except for mainstream gas phase which was 2 runs).

c: The amount of PMO on an unsmoked $23 \mathrm{~mm}$ section would correspond to $27.1 \%$.

* Liquid scintillation counting. 
was considered more convenient than a Hopcalite or silver permanganate column (18).

Initial attempts were made to inject cigarettes containing PMO with a solution of radioactive PMO by use of a microsyringe. Cigarettes were aged, cut into quarters, extracted, and the radioactivity counted. In agreement with recently reported data by Jenkins (19), cigarettes were never uniform in label by this procedure. They showed little improvement on aging, which was somewhat surprising due to the volatile nature of PMO.

Four runs (\# 2, 4, 6 and 7) gave statistically valid data with regard to total material balance. The other runs could be eliminated on the basis of some obvious error or for giving unaccountably low results which on application of statistical tests of data acceptability (20) could be shown to be erroneous at greater than a $95 \%$ confidence level.

In run \# 3, an additional gas bubbler washing bottle containing toluene was placed in the mainstream line after the bottle of sodium hydroxide solution. No radioactivity was detected. This was in agreement with our findings with unlabeled PMO cigarettes in that no detectable mainstream volatiles condensed in cold traps. The puff profile was poor on adjustment to proper puff volume when there were two gas bubbler wash bottles in the mainstream line because of the large ballast. No further runs of this type were made since run \# 3 had already shown no toluene-soluble labeled compounds passing beyond the aqueous sodium hydroxide wash bottle. Table 2 shows that an average of $95.09 \pm 0.58 \%$ of the label was recovered. Table 3 shows the distribution of the label. Comparison with Table $I$ indicates that the PMO undergoing decomposition gives rise to carbon dioxide, carbon monoxide or organic volatiles found almost entirely in the sidestream smoke.

\section{EXPERIMENTAL}

\section{Preparation of Labeled Tobacco}

Cigarettes of approximately $2 \%$ PMO by weight were prepared by the following procedure. Fifty grams of a uniformly cut sample of tobacco which had been
Table 2. Materlal balance results for percentage label recovered as PMO and decomposition productsa.

\begin{tabular}{c|c|c}
\hline Run No. & $\begin{array}{c}\text { \% Recovered label, } \\
\text { excluding }{ }^{14 C O}\end{array}$ & $\%{ }^{14} \mathrm{COd}$ \\
\hline 2 & 94.38 & $\mathrm{C}$ \\
4 & 94.38 & $\mathrm{C}$ \\
6 & 94.57 & 1.11 \\
7 & 94.71 & 2.12 \\
8 & $90.91 \mathrm{~b}$ & 1.21 \\
Average & $94.51 \pm .16$ & $1.48 \pm .56$ \\
Total (including ${ }^{4} \mathrm{CO}$ ) & \multicolumn{2}{|c}{$95.99 \pm .58$} \\
\hline
\end{tabular}

a: $70 \mathrm{~mm}$ clgarettes containing $2 \%$ PMO, smoked to $20 \mathrm{~mm}$ butt length, standard smoking conditions.

b: Statistically eliminated.

c: Not determined.

d: Error large in Co determination. Note that silver oxide-amine solutions are also capable of oxidizing, complexing or otherwise retaining many compounds.

carefully screened by hand to remove overly coarse and fine particles, was added to a stirred solution of $1.02 \mathrm{~g}$ of unlabeled PMO in one liter of distilled hexane. After the mixture was stirred for five minutes, a solution of $20.2 \mathrm{mg}$ of PMO [5-14 $\mathrm{C}$ ] in $18.1 \mathrm{ml}$ of hexane (specific activity $5.055 \mu \mathrm{Ci} / \mathrm{mg}$ ) was added to the stirred mixture over a two-minute period. The slurry was stirred 30 minutes longer and the solvent was removed on a Rinco rotary evaporator at near room temperature. As is possible on the Rinco apparatus, magnetic stirring was introduced near the completion of the rotary evaporation to effect a thorough mixing of the tobacco, and this was continued until all traces of solvent were removed. The tobacco was conditioned one week inside a desiccator over a solution of sodium chloride-sucrose designed to maintain a constant $63 \%$ relative humidity at $25^{\circ} \mathrm{C}$ (2I). The tobacco was mixed and the humidity-regulating solution was changed three times during conditioning.

\section{Preparation of Labeled Cigarettes}

A "Premier Supermatic Cigarette Machine" (Central Tobacco Mfg. Co. Ltd., Canada) set at "plain end"

Table 3. Relative percentage of label found.

\begin{tabular}{|c|c|c|c|c|c|c|c|c|c|}
\hline Run & $\begin{array}{c}\text { Cigarette } \\
\text { welght }\end{array}$ & $\begin{array}{l}\text { Puffs } \\
\text { requir- } \\
\text { ed }\end{array}$ & $\begin{array}{c}\text { Total } \\
\text { mainstream } \\
\text { TPM }^{*}\end{array}$ & $\begin{array}{c}\text { Total } \\
\text { sidestream } \\
\text { TPM }^{*}\end{array}$ & $\begin{array}{c}\text { Totala } \\
\text { butt }+ \\
\text { ash }\end{array}$ & $\begin{array}{c}\text { Mainstream } \\
\mathrm{CO}_{2}\end{array}$ & $\begin{array}{c}\text { Sidestream } \\
\mathrm{CO}_{2}\end{array}$ & $\begin{array}{c}\text { Sidestreamb } \\
\text { organic } \\
\text { volatiles }\end{array}$ & $\begin{array}{c}\text { Sidestreame } \\
\text { CO }\end{array}$ \\
\hline $\begin{array}{l}4 \\
6 \\
7\end{array}$ & $\begin{array}{l}1.0231 \mathrm{~g} \\
0.9584 \mathrm{~g} \\
1.2485 \mathrm{~g}\end{array}$ & $\begin{array}{l}12 \\
12 \\
17\end{array}$ & $\begin{array}{l}25.04 \\
31.44 \\
25.97\end{array}$ & $\begin{array}{l}22.30 \\
24.81 \\
27.30\end{array}$ & $\begin{array}{l}36.72 \\
25.84 \\
25.86\end{array}$ & $\begin{array}{l}0.57 \\
0.73 \\
0.86\end{array}$ & $\begin{array}{r}8.75 \\
10.37 \\
12.93\end{array}$ & $\begin{array}{l}1.00 \\
1.38 \\
1.79\end{array}$ & $\begin{array}{c}d \\
1.11 \\
2.12\end{array}$ \\
\hline
\end{tabular}

a: The amount of label on an unsmoked $20 \mathrm{~mm}$ section would correspond to $28.6 \%$.

b: Mainstream organic volatlles were $0.0 \%$ in run \# 3 .

c: See footnote d, Table 2.

d: Not determined. 
was used to prepare forty cigarettes. After the cigarettes were conditioned at $63 \%$ relative humidity for one week, they were stored in a sealed glass-stoppered bottle kept inside a desiccator.

Compared to commercial cigarettes, the quality of the cigarettes made on the small manually-operated machine was poor because it was not possible to obtain uniform cigarettes of equal weight and degree of compaction. Loss of loose tobacco at both ends of the cigarettes occurred easily. As a result, the relative amounts of tobacco combusted per unit length of cigarette varied. This was reflected in the larger range of puffs required and in the different label ratios observed for mainstream, sidestream, and butt. Although the variation in the relative amounts of label in the mainstream, sidestream, and butt was greater in the hand-made cigarettes, there was good PMO uniformity per unit tobacco weight. Thus the figures for the total amount of label recovered were accurate.

\section{Calibration of Labeled Cigarettes}

One cigarette was withdrawn and weighed by difference in a sealed bottle. Total exposure of the cigarette to ambient air was about five minutes. The entire cigarette was placed in a $33 \times 95 \mathrm{~mm}$ cellulose thimble inside a Soxhlet apparatus. One gram of PMO in $150 \mathrm{ml}$ of distilled hexane was placed in the boiling flask and $50 \mathrm{ml}$ of hexane was placed in the upper chamber. The cigarette weighing bottle was rinsed with two $\mathrm{ml}$ of 2-propanol, and the rinsings were poured into the Soxhlet thimble containing the cigarette and the hexane. Soxhlet extraction was carried out for two hours at such a rate that the chamber was refilled every three minutes. The cooled solution was brought to $250 \mathrm{ml}$ in a volumetric flask. A $5 \mathrm{ml}$ aliquot was pipetted into 10 $\mathrm{ml}$ of $0.4 \%$ Omnifluor (New England Nuclear) in scintillation grade toluene in a liquid scintillation vial. Counting was done as discussed below.

The radioactivity present before any further experiments were performed was found by this procedure to be $1.578 \pm .035 \mu \mathrm{Ci} / \mathrm{g}$ cigarette, based on four determinations. An exact repetition of this calibration procedure after all experiments had been performed showed the presence of $1.584 \pm .023 \mu \mathrm{Ci} / \mathrm{g}$ cigarette, indicating there was no change in activity during storage.

\section{Apparatus Description}

A Filtrona Model 101 12-port smoking machine was connected to the apparatus illustrated in Figure 1. One smoking machine port was attached by means of vacuum rubber tubing to the mainstream gas bubbler washing bottle which, in turn, was connected by Teflon tubing to a Cambridge filter pad holder attached to the mainstream smoking chamber port. The machine was adjusted to take a $35 \mathrm{ml}$ puff over a two-second period once a minute.

A water aspirator was used to carry the sidestream
Figure 1. Gas bubbler washing bottles.

A: Sidestream toluene (organic volatiles). B: Sidestream sodium hydroxide (carbon dioxide). C: Sidestream silver oxide-amine (carbon monoxide). D: Mainstream sodium hydroxide (carbon dioxide).

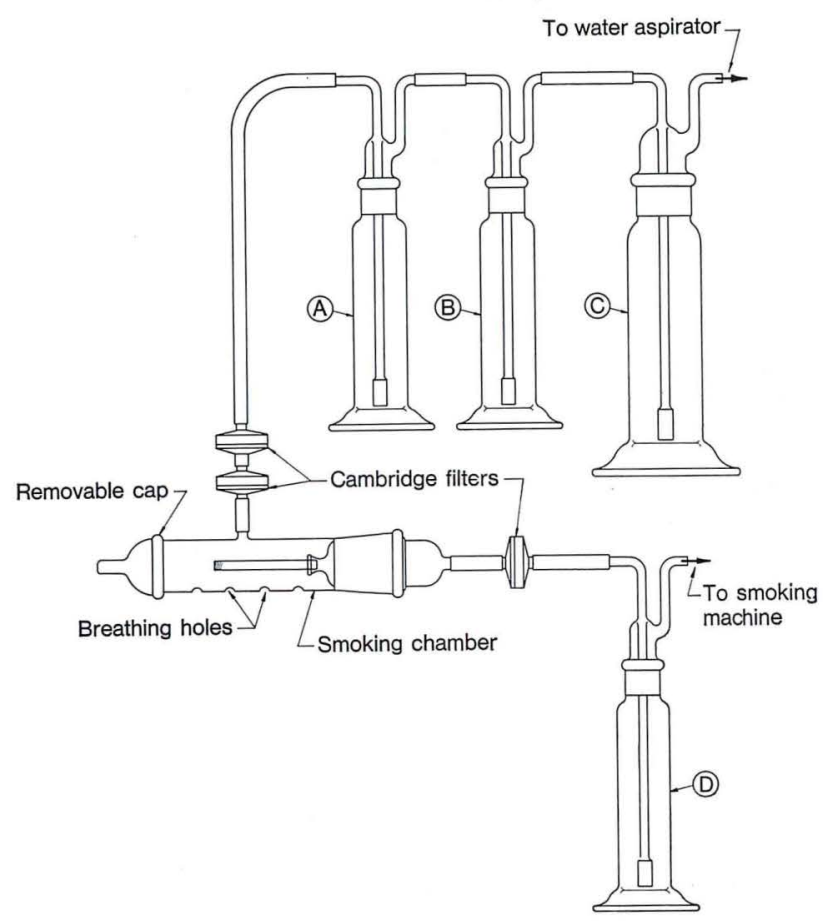

gases through two Cambridge filter pads (Teflon connections) and three gas bubbler wash bottles. A flow rate of one liter per minute of air was maintained. The smoking chamber was constructed totally of Pyrex glass.

The mainstream gas bubbler wash bottle contained $90 \mathrm{ml}$ of $1.2 \mathrm{M}$ sodium hydroxide solution for removal of carbon dioxide and traces of other compounds. The sidestream wash bottles contained, in the order which the smoke passed through them, $90 \mathrm{ml}$ of toluene for removal of volatile organic compounds, $90 \mathrm{ml}$ of $1.2 \mathrm{M}$ sodium hydroxide solution for removal of carbon dioxide, and $250 \mathrm{ml}$ of silver oxide-amine solution for removal of carbon monoxide and other easily oxidizable or complexed compounds. The gas bubbler wash bottles all had glass joints and a submerged coarse glass frit, and were of $250 \mathrm{ml}$ size except for the silver oxideamine bottle which held $500 \mathrm{ml}$. The solution used in this bottle was modified from the literature (17) as follows: $100 \mathrm{ml} 1.5 \mathrm{M}$ sodium hydroxide, $80 \mathrm{ml}$ pyridine, $20 \mathrm{ml}$ concentrated ammonium hydroxide, and $50 \mathrm{ml}$ I $\mathrm{M}$ silver nitrate. The silver nitrate solution was added last while stirring slowly.

Coution! This solution after standing tends to form explosive silver fulminate (22). Care was exercised in its handling. It was prepared freshly and filtered soon after use. The bulk was discarded except for the sample retained for counting.

\section{Lighting and Extinguishing Cigarettes}

After the weighed cigarette was placed in the chamber and the sidestream flow was started, the cigarette was 
lit quidkly by a match held with tweezers while the cigarette machine was taking its first puff. The chamber cover was quickly put back in position. When the cigarette had reached a butt length of $20 \mathrm{~mm}$, it was extinguished by the injection of $0.1 \mathrm{ml}$ of water directly onto the glowing cigarette coal by means of a curved syringe needle introduced, without opening the chamber, through one of the bottom dhamber vent holes. Two more normal cycle clearing puffs were taken before both mainstream and sidestream vacuum sources were disconnected.

\section{Preparation of Solutions for Counting}

Mainstream: The mainstream Cambridge pad was placed in a cellulose thimble in the upper portion of a Soxhlet apparatus. The hexane rinsings of the mainstream pad holder and tubing, and the rinsings of the part of the chamber which had been exposed only to mainstream smoke were placed into the lower portion of the apparatus. PMO $(0.5 \mathrm{~g})$ was added, as was enough hexane to bring the liquid volume to approxinately $200 \mathrm{ml}$. The extraction was carried out for two hours. The cooled extract was brought to $250 \mathrm{ml}$ volume in a volumetric flask. (In one run, the Cambridge pads were extracted a second time with refluxing toluene, but only a negligible amount of label was found.)

The mainstream pad holder, tubing, and appropriate chamber portion were each given a second rinsing with acotone. To the combined rinsings were added $0.5 \mathrm{~g}$ PMO and $10 \mathrm{ml}$ of toluene. The solution was rotary-evaporated to a small volume, and the residue was diluted with toluene to $50 \mathrm{ml}$ in a volumetric flask.

The mainstream aqueous sodium hydroxide solution was brought to $100 \mathrm{ml}$ volume in a volumetric flask.

Sidestream: The preparation of the sidestream solutions was the same as the mainstream solutions, with the following differences: the two Cambridge pads were combined in a single cellulose thimble for extraction. Three gas wash bottles were present in the sidestream line. The toluene from the first wash bottle was brought to $100 \mathrm{ml}$ in a volumetric flask. The sidestream aqueous sodium hydroxide was treated in the manner described for the mainstream. Finally, the precipitated silver metal in the silver oxide-amine wash bottle was removed by filtration through a bed of Celite under water aspirator vacuum behind a safety shield. The volume of this filtrate was recorded. A small amount of the colorless solution was set aside and the rest discarded.

Butt and Ash: A hexane extract of the butt and ash was prepared in a Soxhlet apparatus as described for the mainstream Cambridge pads. In addition, the butt and ash were leached with $50 \mathrm{ml}$ of boiling water poured directly into the thimble. This aqueous extract was brought to $50 \mathrm{ml}$ volume in a volumetric flask.

\section{Liquid Scintillation Counting}

Counting was performed on a Nuclear-Chicago Model 702 instrument set at the widest energy window (950 volts "data" and 7475 volts "gate"). Samples to be counted were prepared by using $10 \mathrm{ml}$ of $0.4 \%$ Omnifluor (New England Nuclear) in toluene and $5 \mathrm{ml}$ of the hexane or toluene solutions. Ten $\mathrm{ml}$ of Aquasol (New England Nuclear) was used to prepare counting mixtures from aqueous solutions. Different amounts of the aqueous solutions to be counted were used so as to maximize gel stability of the counting mixture. For the aqueous sodium hydroxide solutions, $1.0 \mathrm{ml}$ of sample and $2.0 \mathrm{ml}$ of water were used. For the hot water extract of the butt and ash, $3.0 \mathrm{ml}$ of the sample was used. Decomposition was a problem with the silver oxide-amine solution. A mixture containing $2.5 \mathrm{ml}$ of water, $0.3 \mathrm{ml}$ of concentrated ammonium hydroxide and $0.1 \mathrm{ml}$ of sample solution was found to be best for addition to the Aquasol.

Counting solutions were allowed to equilibrate to counting temperature $\left(2^{\circ} \mathrm{C}\right)$ for over two hours. Each sample was placed in counting position for five minutes before counting was initiated. The first sample counted was counted again last as a check on drift. Efficiency of counting was determined for each sample by the addition with a microsyringe of a toluene- ${ }^{14} \mathrm{C}$ internal standard (New England Nuclear) and recounting. The samples were corrected by subtraction of the respective background counts obtained from samples prepared from a blank run with an unlabeled PMO cigarette. The natural radioactivity of the cigarette components including the ash, a source of potassium- $4^{\circ}$, was negligible compared to that of the scintillator solvents and vials.

\section{SUMMARY}

Material balance studies were performed on $85 \mathrm{~mm}$ madhine-made cigarettes containing $1.5 \%$ unlabeled PMO [3-phenyl-5-methyl-1,2,4-oxadiazole], which were smoked under standard conditions to a $23 \mathrm{~mm}$ butt length. Using standard analytical techniques, relative distributions of PMO of approximately $28 \%$ for mainstream, $22 \%$ for sidestream, and $27 \%$ for butt were obtained, with an overall recovery of unchanged PMO of $75-80 \%$. Radiocarbon labeled PMO [5-14 C] cigarettes were prepared manually (70 $\mathrm{mm}, 2 \% \mathrm{PMO}$ ) and smoked under standard conditions to a $20 \mathrm{~mm}$ butt length. Four smoking runs gave statistically valid data accounting for $95.99 \pm 0.58 \%$ of the original label. Measurements of the radioactivity were made by liquid scintillation counting of the various fractions. The mainstream smoke passing through a Cambridge filter pad contained less than one percent of the label as carbon dioxide, and no volatile organic compounds. The PMO undergoing decomposition gave rise to products found almost entirely in the sidestream. 


\section{ZUSAMMENFASSUNG}

Die Masseverteilung wurde an maschinell hergestellten, $85 \mathrm{~mm}$ langen Cigaretten untersucht, die $1,5 \%$ nicht radioaktiv markiertes 3-Phenyl-5-methyl-1,2,4-oxadiazol (PMO) enthielten und unter Standardbedingungen bis zu einer Stummellänge von $23 \mathrm{~mm}$ abgeraucht wurden. Unter genormten analytischen Voraussetzungen fand sich bei einer Wiederauffindungsrate für unverändertes PMO von insgesamt 75-80\% ungefähr die folgende relative Verteilung des PMO: $28 \%$ im Hauptstromrauch, $22 \%$ im Nebenstromrauch und $27 \%$ im Stummel. Radioaktiv markiertes PMO [5- $\left.{ }^{14} \mathrm{C}\right]$ enthaltende, handgefertigte Cigaretten (70 mm, $2 \%$ PMO) wurden unter Standardbedingungen bis zu einer Stummellänge von $20 \mathrm{~mm}$ verraucht. Vier Rauchgänge erbrachten statistisch gesicherte Werte, die $95,99 \pm 0,58 \%$ der ursprünglich zugesetzten Markierung ausmachten. Die Messungen der Radioaktivität wurden durch FlüssigSzintillationszählung in den verschiedenen Fraktionen durchgeführt. Nach Durchgang durch einen CambridgeFilter enthielt der Hauptstromrauch weniger als $1 \%$ der Radioaktivität als Kohlendioxid und keine flüchtigen organischen Verbindungen. Durch Abbauprozesse bildeten sich aus PMO Verbindungen, die fast ausschließlich im Nebenstromrauch zu finden waren.

\section{RESUME}

On a étudié le bilan matière de cigarettes de $85 \mathrm{~mm}$, faites la machine, et contenant $1,5 \%$ de PMO (3-phényl-5-méthyl-1,2,4-oxadiazol) non marqué. On les a fumées sous conditions standard jusqu'à un mégot de $23 \mathrm{~mm}$. Par des techniques analytiques standard, on a obtenu une distribution relative de PMO de $28 \%$ pour le flux principal, $22 \%$ pour le flux secondaire et $27 \%$ pour le mégot, ce qui donne une récupération totale de 75 à $80 \%$ de PMO inchangé. Des cigarettes de $70 \mathrm{~mm}$ contenant $2 \%$ de $\left[5^{-14} \mathrm{C}\right]$ PMO radioactif ont été fabriquées manuellement et fumées sous conditions standard jusqu'à un mégot de $20 \mathrm{~mm}$. Quatre suites de fumage ont produit des données statistiquement valables, récupérant $95,99 \pm 0,58 \%$ du produit marqué. Les mesures de radioactivité ont été faites par comptage de scintillation en milieu liquide sur les différentes fractions. Le flux principal de fumée, passé sur filtre Cambridge, contenait moins de $x \%$ du marqueur sous forme de dioxyde de carbone, et aucun composé organique volatil. Les produits de décomposition du PMO se retrouvent pratiquement en totalité dans le flux secondaire.

\section{REFERENCES}

1. Dalhamn, T.: Amer. Rev. Respirat. Dis. 93, Part 2 (xg66) $x 08$.

2. Dalhamn, T., and R. Rylander: Amer. Rev. Respirat. Dis. 103 (1971) 855.
3. Rylander, R.: Arch. Environ. Health 23 (1971) 321.

4. Dahlgren, S. E., and T. Dalhamn: Acta Pharmacol. et Toxicol. 31 (1972) $x 93$.

5. Jones, R., P. Bolduc, and L. Reid: Brit. Med. J. $1972(2), 142$.

6. Rylander, R.: Scand. J. Resp. Dis. 54 (1973) 223.

7. Jones, R., P. Bolduc, and L. Reid: Brit. J. Exp. Path. 54 (1973) 229.

8. Dalhamn, T.: U. S. Pat. 3, 410, 277, Nov. 12, 1968.

9. Dalhamn, T.: U. S. Pat. 3, 547, 133, Dec. 15, 1970.

I0. Dawson, R. F., R. D. Carpenter, F. L. Gager, Jr., R. W. Jenkins, Jr., and R. H. Newman: Proc. International Tob. Sci. Congress, 5th, Hamburg, Sept. 14-19, 1970, pp. 245-250 (1971); Tob. Abstr. 16 (1972), p. 965, Abstr. 2366.

11. Morrell, F. A., and C. Varsel: Tob. Sci. 10 (1966) 45.

12. Thornton, R. E., and C. Valentine: Beitr. Tabakforsch. 4 (1968) 287.

13. Jenkins, R. W., Jr., R. H. Newman, R. D. Carpenter, and T. S. Osdene: Beitr. Tabakforsch. 5 (1970) 295.

14. Jenkins, R. W., Jr., R. H. Newman, and M. K. Chavis: Beitr. Tabakforsh. 5 (1970) 299.

15. Newman, R. H., W. L. Jones, and R. W. Jenkins, Jr.: Anal. Chem. 41 (1969) 543.

16. Jenkins, R. W., Jr., M. K. Chavis, R. H. Newman, and F. A. Morrell: Int. J. Appl. Radiation and Isotopes 22 (1971) 691.

17. Kolthoff, I. M., and V. A. Stenger: Volumetric Analysis, Vol, 2, p. 294; Interscience Publ., Inc., N. Y., 1947.

18. Katz, M., and S. Halpern: Ind. Eng. Chem. :42 (1950) 345 .

Ig. Jenkins, R. W., Jr., and R. T. Bass: The preparation of carbon- $x_{4}$ labeled cigarettes (Philip Morris Research Center); 27th 'Tobacco Chemists' Res. Conf., Oct. 3-5, 1973, Winston-Salem, N. C.

20. Hindien, J. D.: J. Gas Chromatog. 5 (1967) 641.

21. Winston, P. W., and D. H. Bates: Ecology 4I (1960) 232.

22. Wilson, C. L., and D. W. Wilson: Comprehensive analytical chemistry, Vol. IA, p. 361; Elsevier, N. Y., 1959.

\section{Acknowledgments}

The authors are indebted to Dr. R. B. Patterson and Mr. W. G. Boyd, Ir. for assistance, and to Dr. P. D. Schickedantz for synthesis of labeled PMO $\left.15^{-14} \mathrm{C}\right]$.

The authors' address:

Lorillard Research Center, 420 English Street,

P. O. Box 21688,

Greensboro, North Carolina, 27420, USA. 